\title{
Massive pericardial effusion and pleural effusion: cardiac and pleural infiltration in newly diagnosed acute myeloid leukemia
}

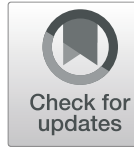

Tao Ma, Hongyun Xing, Xiaofeng Zhu, Pengqiang Wu, Xiaoming Li and Yan Chen * (D)

To the Editor:

Acute myeloid leukemia (AML) is a highly heterogeneous hematologic malignancy and is the most common form of acute leukemia in adults [1]. The main clinical manifestations of AML are infection, fever, hemorrhage, and infiltration. The infiltration sites of AML are more common in the spleen, lymph nodes, and central nervous system, while simultaneous infiltration of AML into the cardiac and pleura is less commonly reported. We treated a patient with AML infiltrating both the cardiac and pleura. The patient developed malignant arrhythmia and severe dyspnea, and after we gave the patient percutaneous pericardial drainage and chemotherapy, the patient's symptoms were relieved and AML was controlled.

A 51-year-old man with more than 10 days of fatigue, dizziness, was admitted to our hospital. Through morphology, immunology, cytogenetics, and molecular biology, he was diagnosed with AML1-ETO leukemia. On admission, the electrocardiogram (ECG) of the patient was normal, and a small pericardial effusion was observed on CT (Fig. 1 (1A)). One week later, there was a significant increase in pericardial effusion and a right pleural effusion (Fig. 1 (1B)). Ten days after admission, the patient had obviously difficult breathing and palpitations, and ECG indicated frequent ventricular premature beat, CT showed massive pericardial effusion and pleural effusion (Fig. $1(2 \mathrm{~A}, 2 \mathrm{~B}))$. Massive pericardial effusion was seen in the bedside echocardiogram, and in the pericardium cavity, a large number of fibrous strips can be seen, some of which were honeycombed. The blood routine indicated that white blood cells were $43 \times 10^{9} / \mathrm{L}$, hemoglobin was $62 \mathrm{~g} / \mathrm{L}$, and platelets were $21 \times 10^{9} /$
L. To relieve the patient's symptoms, percutaneous pericardial drainage and indwelling catheter were performed, and $500 \mathrm{ml}$ of dark red pericardial effusion was drained. At the same time, HA (homoharringtonine plus cytarabin) regimen was used to control AML. Leukemic cells accounted for $12 \%$ on pericardial effusion smear and $6.71 \%$ on flow cytometry analysis of pericardial effusion (Fig. 1 (3A, 3B)). From these two tests, we were able to consider that massive pericardial effusion was caused by leukemic cells infiltration of the heart. Flow cytometry analysis of pleural effusion showed that leukemia cells accounted for $6.61 \%$ (Fig. 1 (3C)). From this examination, we knew that leukemic pleural infiltration was one of the reasons of pleural effusion. One week after the chemotherapy, the patient's condition improved and the pericardial puncture tube was planned to be removed (Fig. 1 (3D)). AML achieved complete remission after 1 month of chemotherapy, and pericardial effusion and pleural effusion were significantly reduced (Fig. $1(4 \mathrm{~A})$ ). The patient was discharged. Reexamination 1 month after discharge revealed only a small amount of pericardial effusion (Fig. 1 (4B)).

Acute leukemia infiltrates the heart with myocardial thickening, heart failure, etc. [2, 3]. We reported a patient with simultaneous cardiac and pleural infiltration, characterized by massive pericardial effusion and pleural effusion. Flow cytometry is reliable in the diagnosis of leukemic infiltration with pericardial effusion. The treatment of acute leukemia infiltrates the heart is to reduce the patient's symptoms as well as to chemotherapy for leukemia.

\footnotetext{
* Correspondence: chenyan1211@swmu.edu.cn

Haematology Department, Affiliated Hospital of Southwest Medical

University, Luzhou, China
} 

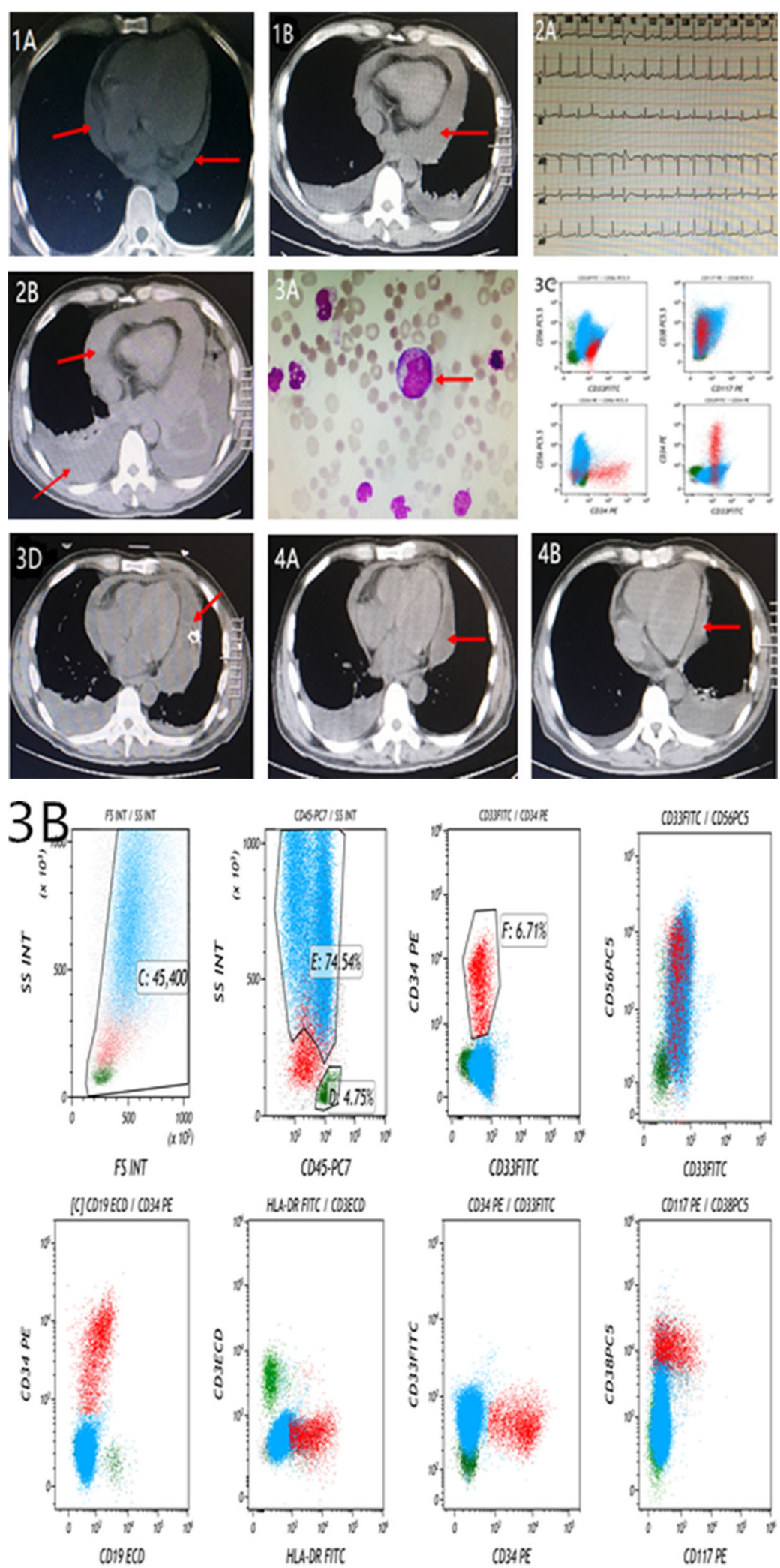

Fig. 1 (See legend on next page.) 
(See figure on previous page.)

Fig. 1 Summary of main laboratory parameters of the patient. 1A On admission, a small amount of pericardial effusion was found on CT examination. 1B One week after admission, the patient had a significantly increased pericardial effusion and a right pleural effusion. 2A Ten days after admittance, ECG suggested frequent premature ventricular contractions. 2B Ten days after admission, pericardial effusion and pleural effusion further increased. 3A A smear of pericardial effusion showed leukemic cell. 3B Leukemic cells were found by flow cytometry analysis of pericardial effusion. 3C Leukemia cells were found by flow cytometry analysis of pleural effusion. 3D The patient was placed with a pericardiocentesis drainage tube. 4A One month after chemotherapy, the patient's pericardial effusion was significantly reduced. 4B Reexamination 1 month after discharge revealed only a small amount of pericardial effusion

\section{Abbreviations}

AML: Acute myeloid leukemia; ECG: Electrocardiogram;

HA: Homoharringtonine plus cytarabin

\section{Acknowledgements}

Not applicable.

\section{Authors' contributions}

M drafted the work, Z, X, W, and L collected data, C revised this work. All authors have read and approved the manuscript.

\section{Funding}

This study was funded by Southwest Medical University (grant number 15015).

Availability of data and materials Not applicable.

\section{Declarations}

\section{Ethics approval and consent to participate}

This article does not contain any studies with human participants or animals performed by any of the authors.

\section{Consent for publication}

Not applicable.

\section{Competing interests}

Author Tao Ma declares that he has no conflict of interest. Author Hongyun Xing declares that he has no conflict of interest. Author Xiaofeng Zhu declares that she has no conflict of interest. Author Pengqiang Wu declares that he has no conflict of interest. Author Xiaoming Li declares that he has no conflict of interest. Author Yan Chen declares that she has no conflict of interest.

Received: 19 April 2021 Accepted: 4 August 2021

Published online: 01 September 2021

\section{References}

1. De Kouchkovsky I, Abdul-Hay M. 'Acute myeloid leukemia: a comprehensive review and 2016 update'. Blood Cancer J. 2016;6(7):e441. Published 2016 Jul 1.

2. Baritussio A, Gately A, Pawade J, Marks DI, Bucciarelli-Ducci C. Extensive cardiac infiltration in acute T-cell lymphoblastic leukemia: occult extramedullary relapse and remission after salvage chemotherapy. Eur Heart J. 2017;38(24):1933. https://doi.org/10.1093/eurheartj/ehw393.

3. da Silva GL, Valle S, Pinto FJ, Almeida AG. Leukaemic myocardial infiltration presenting as acute heart failure. Eur Heart J Cardiovasc Imaging. 2015;16(4): 460. https://doi.org/10.1093/ehji//jeu301.

\section{Publisher's Note}

Springer Nature remains neutral with regard to jurisdictional claims in published maps and institutional affiliations.

\section{Submit your manuscript to a SpringerOpen ${ }^{\circ}$ journal and benefit from:}

- Convenient online submission

- Rigorous peer review

- Open access: articles freely available online

High visibility within the field

- Retaining the copyright to your article

Submit your next manuscript at $\boldsymbol{\nabla}$ springeropen.com 